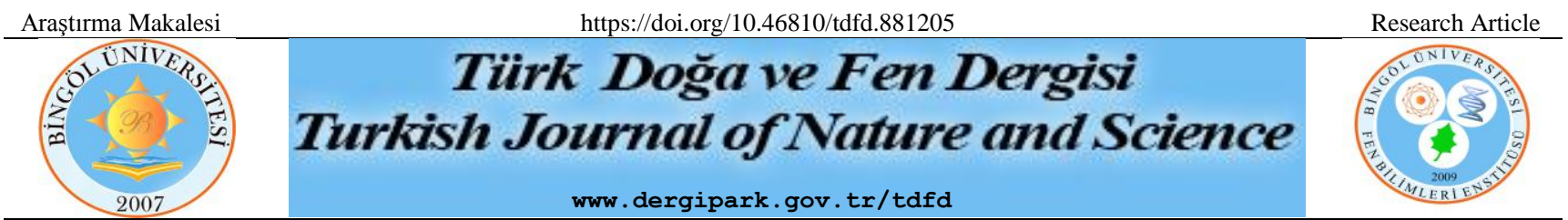

\title{
Estimation of Upper Extremity Movement Performance in Stroke Patients with Artificial Learning Techniques
}

\author{
Mücahit ÇALIŞAN ${ }^{1 *}$, Muhammed Fatih TALU ${ }^{2}$ \\ ${ }^{1}$ Bingöl Üniversitesi, Enformatik Bölümü, Bingöl, Türkiye \\ ${ }^{2}$ İnönü Üniversitesi, Mühendislik Fakültesi, Bilgisayar Mühendisliği Bölümü, Bingöl, Türkiye \\ Mücahit ÇALIȘAN ORCID No: 0000-0003-2651-5937 \\ Muhammed Fatih TALU ORCID No: 0000-0003-1166-8404 \\ *Sorumlu yazar: mcalisan @bingol.edu.tr
}

(Alınış: 16.02.2021, Kabul: 8.04.2021, Online Yayınlanma: 25.06.2021)

\begin{abstract}
Keywords
Brunnstrom

Staging,

Stroke,

Machine

Learning,

Accelerometer

Abstract: The main reason why people are directed to rehabilitation services after stroke-like neurological diseases are to bring individuals' daily abilities to a normal level. Measuring the activities of people in their daily lives ensures that these rehabilitation services progress more healthily. In our study, Brunnstrom Hemiplegia Recovery Staging, which is widely used by doctors to evaluate the movement function of stroke patients during rehabilitation, was examined. The study was specifically adapted to the upper extremity stage 4a movement of the Brunnstrom Staging. Daily movements of patients were evaluated with accelerometer sensors. With this methodology, sensor data was collected from 15 volunteer stroke patients and 80 healthy individuals. These sensor data were interpreted by the medical professional. Thus, consistency between movement data of healthy and sick individuals was analyzed. The data obtained as a result of the analysis process were examined with artificial learning methods and classified as healthy/unhealthy. The methodology of the study is suitable for research designed to increase upper / lower extremity performance in the daily life of individuals.
\end{abstract}

\section{İnmeli Hastalarda Üst Ekstremite Hareket Başarımının Yapay Öğrenme Teknikleri ile Kestirimi}

\section{Anahtar \\ Kelimeler \\ Brunnstrom \\ Evrelemesi, \\ İnme, Makine \\ Öğrenmesi, \\ İvmeölçer}

Öz: İnme benzeri nörolojik hastalıklardan sonra kişilerin rehabilite hizmetlerine yönlendirilmesinin ana nedeni, bireylerin günlük yaşamdaki yeteneklerini normal düzeye çıkartmaktır. Kişilerin günlük yaşamlarındaki faaliyetlerini ölçmek bu rehabilitasyon hizmetlerinin daha sağlıklı ilerlemesini sağlamaktadır. Çalışmamızda doktorlar tarafından rehabilitasyon sırasında inme hastalarının hareket işlevini değerlendirmek için yaygın olarak kullanılan Brunnstrom Evrelemesi incelenmiştir. Çalışma özgül olarak Brunnstrom Evrelemesi testinin üst ekstremite bölümü 4a hareketine uyarlanmıştır. Hastaların günlük hareketleri ivmeölçerler sensörleri ile değerlendirilmiştir. Bu çalışmada izlenilen metodoloji ile gönüllü 15 inme hastası ve 80 sağlıklı bireyden sensör datası toplanmıştır. Elde edilen sensör verisi medikal uzman tarafindan yorumlanmıştır. Böylece sağlıklı ve hasta bireylerin hareket verileri arasındaki tutarlılıklar analiz edilmiştir. Analiz işlemi sonucunda elde edilen veriler yapay öğrenme yöntemleriyle incelenmiş ve sağlıklı/sağlıksız şeklinde sınıflandırılmıştır. Çalışmanın metodolojisi kişilerin günlük yaşamlarında üst/alt ekstremite performansını arttırmak için tasarlanmış araştırmalar için uygundur.

\section{INTRODUCTION}

Stroke, according to the World Health Organization (WHO), is ranked third among all causes of death in 2008, after heart disease and cancer. Also, it is the most common neurological disorder that causes disability in adults [1]. Changing the lifestyle of individuals causes an increase in cerebrovascular disorders. Accordingly, it has become an important cause of death and disability worldwide. Prolonged life expectancy in developed countries has increased neurological diseases such as stroke. The prevalence of stroke disease in society over 60 years of age has been reported as 500-600/ 100000 in 
western society and 900/100000 in Asian countries [2]. Prevention and treatment of stroke are very important in our country where the elderly population is increasing because the frequency of this disease in our country is around 176/100000 [2].

The proportion of people dying from diseases caused by stroke or moving away from society is increasing day by day around the world. This increase also causes a significant share of health expenses. Estimated direct or indirect spending for stroke is around $\$ 73$ million in the US, which is around \$ 64 million in Europe in 2010 [3, 4]. In Asian countries such as China, approximately 2 billion dollars of health expenditure is observed every year. Despite the progress made in the treatment of stroke diseases, this type of disease affects a serious population in society and causes significant physical losses in survivors. After the stroke, approximately 70\% of patients experience impairment in upper limb functions and $40 \%$ suffer permanent loss in the affected upper limb functions [5].

The purpose of rehabilitation services for people with neurological problems such as stroke is to improve their skills not only in the clinic but also in daily life. The ultimate goal in rehabilitation; Despite current deficiencies, it is aimed at gaining the highest level of functional independence to the individual and increasing the quality of life. Editing the patient's rehabilitation prescription in the rehabilitation process depends on the assessments predicted by physical therapists. Of course, since this evaluation process is not quantitative, it is common for medical professionals to make different evaluations.

Research shows that intensive and repetitive exercises are more useful to improve the improvement of motor functions after stroke. In stroke rehabilitation, it is very important to perform the exercises fully, correctly and appropriately. For this reason, the systems to be used must follow the patient's movements accurately, precisely and appropriately and then give feedback on performance to the experts [6]. Due to the increase in medical expenditures and an insufficient number of rehabilitation specialists; Low-cost home treatment methods are needed for the rehabilitation of stroke patients. For this purpose, in addition to today's treatments, computer-based systems have been used in the rehabilitation of patients with stroke. This shows that the interest in wearable sensors is increasing day by day. Accelerometer sensors are of great interest in the field of rehabilitation. The different axes $(x, y, z)$ of these sensors correspond to accelerations such as human motion and measure and record these movements in three dimensions. These devices, which are available on the market, can be used without any restrictions on people's daily activities. The World Health Organization divides the international function classification into two as clinical and non-clinical settings [7]. The accelerometer sensor provides a measurement of upper extremity performance in non-clinical settings. Our study describes the extremity measurement methodology that can be used in both clinical and non-clinical settings.
The methodology is based on the analysis of signals obtained from accelerometers connected to certain body parts. The sensors used are valid and reliable tools for measuring upper limb performance following stroke and similar neurological conditions. Of course, this performance measurement has certain difficulties. Converting raw accelerometer data to clinically relevant information is one of these challenges. The methodology proposed in the study can be used to differentiate healthy participants' upper limb performance from stroke participants.

When the related studies are examined, it is seen that the use of accelerometers and similar sensors increases day by day in medical applications. Evanthia E. Tripoliti et al. 6 accelerometers and 2 gyroscopes were used and $96.11 \%$ accuracy rate was obtained. During the study, accelerometers were attached to the wrist, ankles, chest and waist. Gyroscopes were attached to the participants' chest and waist [8]. G Rigas et al. proposed an automated method for both rest and motion/vibration assessment using accelerometers attached to different parts of the Parkinson's patient's body [9]. Sinziana Mazilu et al. a total of 6 accelerometer sensors were attached to the wrists, ankles and knees of the participants. In these studies, where they obtained 90\% accuracy rate, they tried to detect Parkinson's disease from the speed of movement in hand and foot movements [10]. C Ahlrichs et al. achieved an accuracy rate of $98.7 \%$ by examining the movements and speed of individuals with the help of 3-axis sensors placed on the waist of the participants [11]. To classify hand movements with electromyography (EMG) sensors, which have a working logic close to accelerometer sensors, 2-channel EMG data has been classified with deep learning methods [12]. In addition, many researchers have used the accelerometer $[13,14,15]$, gyroscope [16], handwriting and drawing samples [17], electromagnetic tracking [18]. A laser system that converts velocity has been developed to detect and evaluate tremor activity [19]. Also, most of the studies mentioned above have several limitations. For example, in most studies, some limitations, such as the collection of data only inappropriate laboratory settings or using simulated data, do not make it possible to apply methods in real-life conditions.

In this study, the effect of Xsens sensors on the interpretation of upper limb movements in stroke patients was evaluated. Wearable sensors are attached to the body so that the accelerometer data of the upper limb activities can be collected. Sensors containing accelerometers, gyroscopes and magnetic field meters have high memory and processing power by using less energy. Since the exercise is targeted to be detected, only accelerometer sensor data is used. Accordingly, $x, y, z$ acceleration values on three axes are recorded while performing the exercise. Machine learning methods were used to match the recorded accelerometer data to the diseased or healthy group. For this, the methodology of the study is as follows; to obtain the data, to pre-process the data, to build the network and to classify the exercise to the relevant group. The following section describes 
the basic steps of the methodology. The results of the method are given in section 3 and these results are discussed in section 4 .

\section{MATERIALS AND METHODS}

In this study, which includes accelerometer sensor-based exercise recognition, the methodology shown in Figure 2 was followed. Accordingly, accelerometer sensor data were collected from patients and healthy individuals who performed the relevant activity of the Brunnstrom test. These acceleration signals were pretreated and motion properties were calculated. Sensors are placed in the subjects' bodies in different positions. The sensor placement on the subjects was shown in Figure 1.

\subsection{Data Groups}

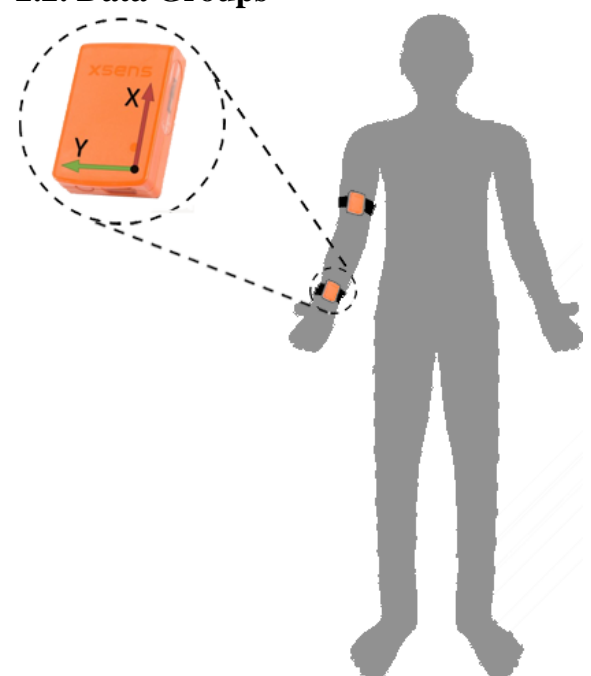

Figure 1. Sensor placement in the subjects' bodies

Various features related to time and frequency domain characteristics were extracted from the recorded signals to evaluate the relevant exercise of Brunnstrom Staging. Finally, it was determined which group of the individual's exercise belongs to by different classification methods. Today, there are many clinical evaluation methods such as the Fugle-Meyer method, Bobath Level Method, and Brunnstrom Staging [20]. Since the Brunnstrom Staging method has the advantage of simplicity and time saving, the Brunnstrom stage method was used as the evaluation criterion in this study.

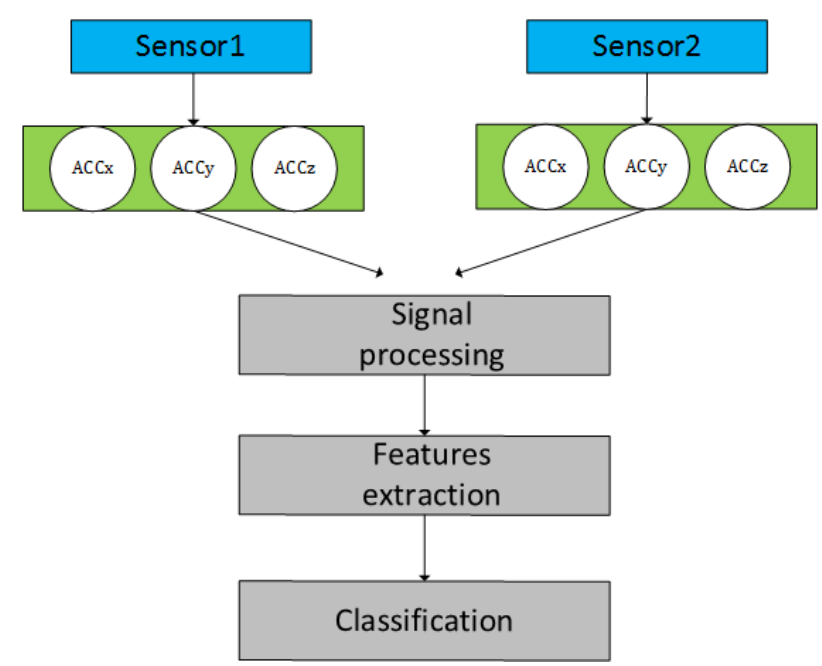

Figure 2. Recommended Exercise Recognition Process

\subsection{Brunnstrom Motor Staging (BMS)}

The Brunnstrom test, which evaluates the motor development of stroke patients, was described by Signe Brunnstrom in 1966. The purpose of the test is to identify the recovery stages observed in too many hemiplegic patients. In this staging, the upper limb and lower limb are evaluated separately and the healing process of the stroke patient is defined as 7 stages. The lowest stage according to this staging is stage 1 (flask, stage with no movement); the highest stage was determined as stage 7 (stage with normal motor function). High Brunnstrom stages show that motor development is better than other stages. Specifically, the Stage- 4 movement of BMS was taken in the study. Stage 4 is given in Table 1 .

Table 1. Brunnstrom Hemiplegia Recovery Staging (Stage-4)

\begin{tabular}{|l|l|}
\hline Stage-4 & $\begin{array}{l}\text { Isolated movements different from motion synergies } \\
\text { gradually emerge and become more evident. Spasticity } \\
\text { decreases, but spasticity continues on isolated } \\
\text { movements. Observed isolated movements: } \\
\text { a) Touching the hand to the back of the body and the } \\
\text { sacral region } \\
\text { b) 90-degree flexion of the shoulder with the elbow in } \\
\text { extension } \\
\text { c) Supination and pronation when the elbow is at } 90 \\
\text { degrees flexion and the arm is close to the body }\end{array}$ \\
\hline
\end{tabular}

\subsection{Data Groups}

In the study, 15 stroke patients were evaluated and they were hospitalized to be rehabilitated in Bingöl State Hospital Physical Medicine and Rehabilitation Clinic between 01.09.2019-30.12.2019. In the study, data was collected from 80 healthy individuals. Thus, two separate data groups were created as Healthy and Patient.

The criteria in the people included in the research; they should not be over the age of 60, they should be within the first 1 year after stroke, and the most important is that the upper extremity is stage 3 and above according 
to BMS. The demographic characteristics of the patients and healthy people by these criteria are given in Table 2 . Not all patients have serious cognitive and communication problems. The situations that may cause problems before and during the experiments were taught to the patients in detail by the doctors.

Table 2. Demographic characteristics of patients and healthy people

\begin{tabular}{|c|c|c|c|}
\hline & & Healthy & Patient \\
\hline Age (Year) & & $25-45$ & $20-60$ \\
\hline $\begin{array}{l}\text { Disease } \\
\text { (Month) }\end{array}$ & period & - & $3-12$ \\
\hline Gender & & $\begin{array}{l}\text { Woman }(\% 36.25) \\
\text { Man }(\% 63.75)\end{array}$ & $\begin{array}{l}\text { Woman }(\% 40) \\
\text { Man }(\% 60)\end{array}$ \\
\hline
\end{tabular}

Before starting the stage 4 movement, the patient and healthy individuals were informed by the physiotherapist about the movement and exactly how to do the movement was shown. In Figure 3, it is seen that Xsens sensors are placed in the arm of the expert and the Stage4 exercise is performed 5 times repeatedly. This movement was also recorded on video. Thus, even in environments where there is no expert person, people can see how to do the movement.
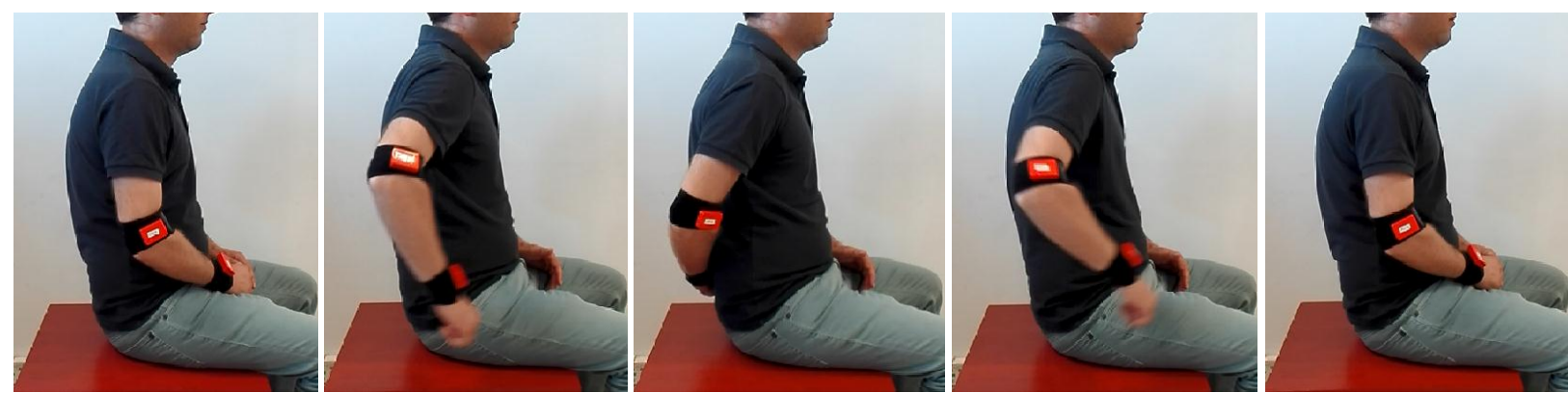

movements, (e) Exercise end position

Accelerometers are attached to the wrist and elbow parts of the participant, and flexible sensor straps are used depending on whether the person is overweight or weak. Healthy participants were watched in the exercise video in Figure 3. However, the exercise has been demonstrated by the specialist to the patients. All individuals were asked to complete the exercise without any help to reflect their real movement functions. Before the experiments, the patients were asked to repeat the same movement several times to recognize the experimental process. During the experiments, all patients were asked to perform the movement 5 times and consecutively.

\subsection{Data Set Construction}

In this study, which aims to determine the relevant exercise of the Brunnstrom test, commercially available MTw inertial sensors from Xsens were used. This sensor can provide a 3-axis gyroscope, 3-axis accelerometers and 3-axis magnetometer data instantaneously. MTw, which can operate for 6 hours with a LiPo battery, can be easily placed on the body with the help of flexible hooks and loop straps. Data from MTw can be transferred to the computer with the help of a wireless adapter. To save the data transferred to the computer, MT Manager software published by Xsens free of charge was used. Figure 4 shows the interface of the MTw sensor and data acquisition software.
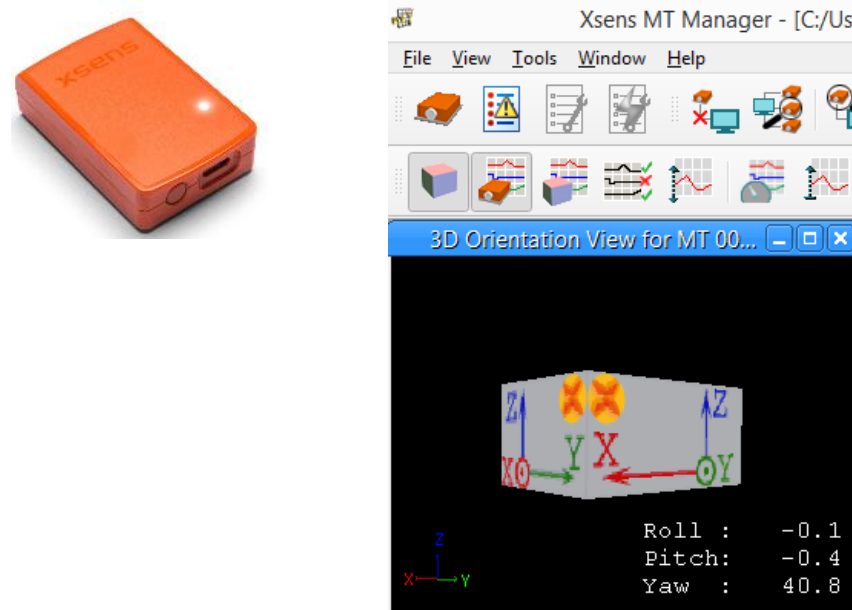

(a)

Figure 4. Xsens MTw Awinda sensor and software a) MTw motion tracker; b) MT Manager software 
In the study, three-axis accelerometer data obtained from MTw was used to create the data set. MTw sensors are set to receive data at $100 \mathrm{~Hz}$ sampling frequency. Thus, $100 \mathrm{~Hz} \times 3$ (axis) = 300 acceleration information was recorded per second. Some of the sensor data of the Stage-4 movement collected from a healthy individual is given in Table 3.

Table 3. Data of Xsens MTw accelerometer sensors

\begin{tabular}{llll}
\hline Index & ACC_x & ACC_y & ACC_z \\
\hline 0 & -4.506073 & 8.561544 & 2.043696 \\
1 & -4.486872 & 8.634863 & 2.032347 \\
2 & -4.469610 & 8.505292 & 2.065711 \\
3 & -4.484636 & 8.300303 & 2.133130 \\
$\ldots$ & $\ldots$ & $\ldots$ & $\ldots$ \\
\hline
\end{tabular}

To obtain the data, 80 healthy and 15 patients with MTw sensors were asked to repeat the relevant exercise of the Brunnstrom test 5 times (to obtain reliable kinematics). Sensors are placed in the relevant parts of the arm determined by the physiotherapist. While exercise periods are done between $15-20$ seconds in healthy individuals, this period naturally gets longer in sick individuals. Considering the age and stroke time of individuals, exercise times may vary from individual to individual. The time-domain representation of the Stage4a exercise sensor data received with accelerometer signals from healthy and sick people is given in Figure 5.
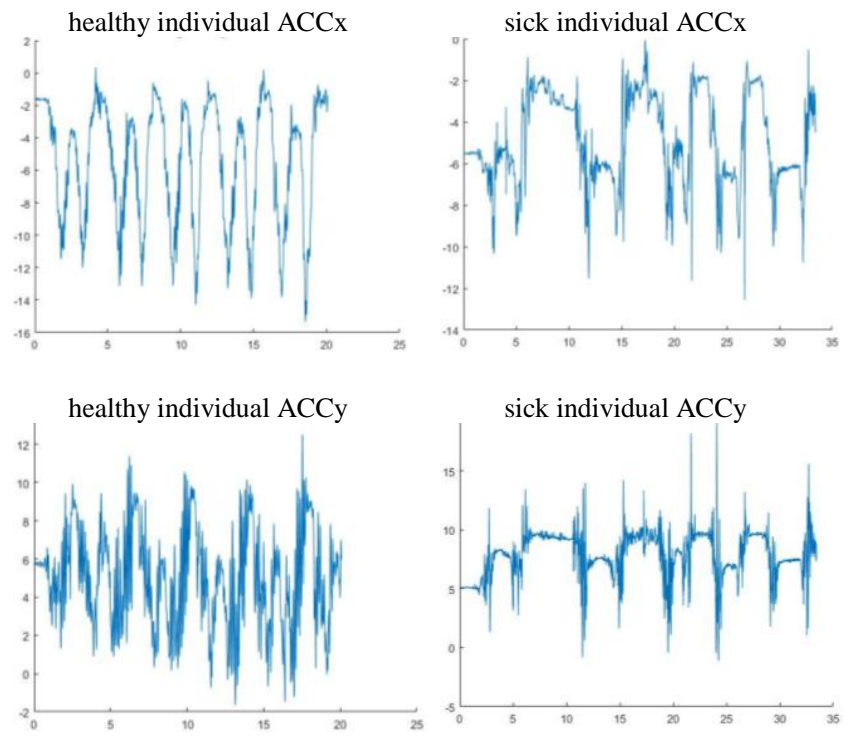

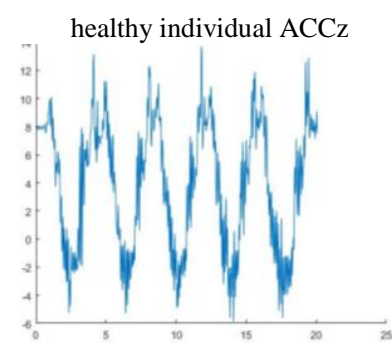

ime (sn)

(a)

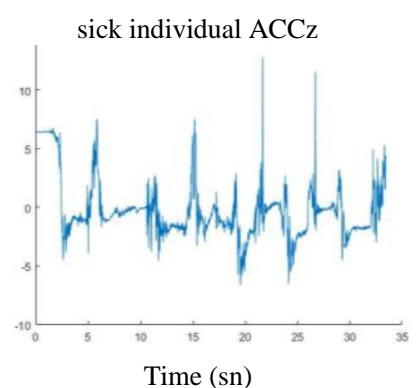

(b)
Figure 5. Time-domain signals of (a) Healthy and (b) Patient individuals with MTw sensor

The accelerometer signals given as two columns $(\mathrm{a}, \mathrm{b})$ in Figure 5 were taken from healthy and patient individuals. These received signals belong to one random person from the healthy and patient clusters. Figure 5a column shows the data of a healthy individual and Figure $5 \mathrm{~b}$ column shows the data of the patient. The received $x, y, z$ coordinate signals are defined as properties. The local analysis deals with signal features in a small interval, such as a few seconds. The global analysis covers a wider range. When focusing on the local analysis part of the signals, a similar distance of the peak areas shows that the signal belongs to a healthy individual. The irregularity of the peak areas is clearly seen in patient individuals. When looking at the global analysis section, it is seen in healthy individuals that the signal has five repetitions. The number of repetitions cannot be determined in patient individuals.

As can be seen from the accelerometer signal shapes $(x, y, z$ directions) given in Figure 5, it was observed that the signal progressed in a certain order during the Stage4a movement in a healthy person. It was observed that there was a relatively random oscillating signal structure in the signals of the patient individuals.

\subsection{Feature extraction}

Real-time data from the accelerometer reduces data accuracy, as it contains noisy sensor samples. By using a median filter, this data can be transformed into a more useful way by removing noise. The median filter performs a nonlinear filtering operation in which a window moves over a signal, and the median value of the data in the window is output at each point. This value, which is in the middle of the data sorted from small to large, is expressed as the aggregation measure to the center.

The median of $N$ data is $X_{i}, i=1, \ldots, N$ can be defined as $X_{m d y}$ value for all $y . X_{m d y}$ can always be selected as one of $X_{i}$

$$
\sum_{i=1}^{N}\left|X_{m d y}-X_{i}\right| \leq \sum_{i=1}^{N}\left|y-X_{i}\right|
$$

As an example, the raw (blue line) and noise-reduced (orange line) data of healthy and patient individuals are shown in Figure 6. After filtering, noise-free data appears to be smoother than raw data. In both signals, the same part of the time domain was selected.

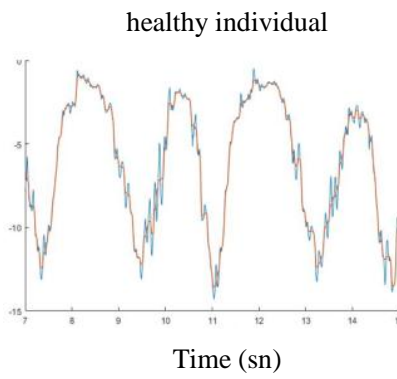

(a)

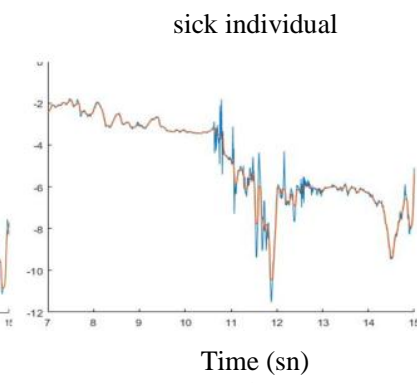

(b)
Figure 6. Time-domain signals of (a) Healthy and (b) Sick individuals

Since the upper limb movements of stroke patients are limited, they cannot complete the exercises properly. 
This means that the sample data is included in some irrelevant data as well as useful raw data. As a result, variance, mean square root, maximum value, string length, etc. Some typical features, such as those that can represent the natural property of the motion function, must be removed. It is very important to deduce these features in terms of the efficiency of classification. In the study, feature extraction is performed for the time domain. In this study, mean acceleration values, deviation values of acceleration, peaks of the signal and local binary pattern (LBP) were used in the $\mathrm{x}, \mathrm{y}, \mathrm{z}$ axes. In Table 4 , the signal properties received from the three axes of the two sensors are given.

Table 4. Features and explanations

\begin{tabular}{lcc}
\hline Explanations & Sensor 1 & Sensor 2 \\
\hline $\begin{array}{l}\text { Average acceleration } \\
\text { values in x, y and z axes }\end{array}$ & $\mu_{x}, \mu_{y}, \mu_{z}$ & $\mu_{x}, \mu_{y}, \mu_{z}$ \\
$\begin{array}{l}\text { Deviation values of } \\
\text { acceleration in } \mathrm{x}, \mathrm{y} \text { and } \mathrm{z} \\
\text { axes }\end{array}$ & $\sigma_{x}, \sigma_{y}, \sigma_{z}$ & $\sigma_{x}, \sigma_{y}, \sigma_{z}$ \\
$\begin{array}{l}\text { Peak peaks of the signal } \\
\text { in x, y and z axes }\end{array}$ & $F_{x}, F_{y}, F_{z}$ & $F_{x}, F_{y}, F_{z}$ \\
Local binary pattern & $L B P_{x}, L B P_{y}, L B P_{z}$ & $L B P_{x}, L B P_{y}, L B P_{z}$ \\
\hline
\end{tabular}

When performing Brunnstrom Stage-4 by individuals, activity is defined as the sum of absolute values of ACC signals in all directions.

$$
\text { Aktivite }=\sum_{i}^{n}\left(\left|A C C_{x}^{i}\right|+\left|A C C_{y}^{i}\right|+\left|A C C_{z}^{i}\right|\right)
$$

where $A C C_{x}, A C C_{y}, A C C_{z}$ are the accelerometer components of the $x, y, z$ axes, respectively; $n$ is the number of samples of a given signal length. In this study, the following features were obtained.

Average acceleration values: The average vector between the three axes can be expressed as follows.

$$
\bar{a}_{i}=\frac{1}{N} \sum_{t=1}^{N} a_{i}(t)
$$

where $i$ represents the axes $(i=x, y, z)$

Deviation values of acceleration: Standard deviation is used to capture the fact that the range of acceleration values of the activities of healthy and sick individuals is different.

$$
S=\sqrt{\frac{1}{|W|-1} \sum_{i=1}^{|W|}\left(a_{i}-m\right)^{2}}
$$

where $W$ is the length of the repetitive movement $4 \mathrm{a} . a_{i}$ is an example of acceleration. $m$ is the average value of $a_{i}$.

Signal peaks: Returns a vector that is the local maximum (peaks) of the input signal vector. This peak is the data value that is larger than two adjacent instances. Returns the peaks of $A C C_{x}, A C C_{y}, A C C_{z}$ in order $F_{x}, F_{y}, F_{z}$.
Local binary pattern: LBP captures the local distribution of the signal by comparing a sample with its neighbor and encoding the data into binary states. It is widely used for LBP image analysis and has proven to be very effective. Recently, researchers have also explored the effectiveness of LBP for a one-dimensional signal [21]. In one-dimensional LBP, a neighborhood window is defined on the accelerometer data. However, neighborhood values correspond to the previous and next readings in the accelerometer signal instead of the pixel proxies in the images. For each data sample in a signal, a binary code is generated by matching its value with the central value. This process is repeated on the entire signal. One-dimensional LBP formulation on an example is as follows.

$$
L B P(x)=\sum_{i=0}^{P} F(t) 2^{i}, \quad F(t)=\left\{\begin{array}{l}
1, t \geq 0 \\
0, t<0
\end{array}\right.
$$

where $t=P_{i}-P_{c} . P_{i}$ represents the neighbor number, $P_{c}$ represents the center point.

\section{MACHINE LEARNING METHODS}

In classification problems, it is important to select the appropriate classifier after the feature vectors are calculated. In the study, the movements of healthy and sick people are recognized. The task of motion recognition algorithms is to classify the input signal model into one of the given motion classes. In this study, K-Nearest Neighbors (KNN), Support Vector Machine (SVM) and Artificial Neural Networks Classifier (ANN) are used. In the study, the performance of these thre classifiers was compared. KNN, SVM and ANN algorithms have been used successfully with varying success rates in defining Brunnstrom activities.

\subsection{K-nearest neighbors (KNN)}

$\mathrm{KNN}$ is one of the statistical classification algorithms used to classify objects according to the closest training examples in the property area. No real model or learning is made during the training phase, it only uses one instance of the search field to fill the class with known examples. Euclidean distance measurement was used to calculate the distance between the target sample and other samples in the property space. In the KNN algorithm, the training phase is very fast, but the testing phase is costly in both time and memory.

$$
d(p, q)=\sqrt{\sum_{i=1}^{n}\left(p_{i}-q_{i}\right)^{2}}
$$

where $d(p, q)$ is the distance between samples $p$ and $q . p_{i}$ and $q_{i}$ for example $i$. is the property and $n$ is the number of properties. 


\subsection{Support vector machine (SVM)}

SVM is a classifier derived from statistical learning theory. This classifier is a good choice for highdimensional areas. In their standard formulations, SVMs are linear classifiers. Also, nonlinear classification can be accomplished by extending SVM using kernel methods. This classifier has been successfully applied to solve problems in many areas such as object, sound, fingerprint and handwriting recognition [21].

The KNN and SVM models used in this study are given in Table 5. Experimental applications were carried out for each of these models and the best classifier model was tried to be selected.

Table 5. Functions of KNN, SVM models

\begin{tabular}{ll}
\hline k-NN Modelleri & SVM Modelleri \\
\hline Fine KNN & Linear SVM \\
Medium KNN & Quadratic SVM \\
Coarse KNN & Cubic SVM \\
Cosine KNN & Fine Gaussian SVM \\
Cubic KNN & Medium Gaussian SVM \\
Weighted KNN & Coarse Gaussian SVM \\
\hline
\end{tabular}

\subsection{Artificial Neural Networks (ANN)}

Artificial Neural Network is a computational model consisting of interconnected artificial neurons. ANNs are able to model complex relationships between inputs and outputs. Similar to the KNN approach, the ANN is also a flexible and powerful architecture. ANN has the potential to be used for a range of different classification problems.

\section{EXPERIMENTAL RESULT}

In the study, the classification of the related activities of Brunnstrom Staging of healthy and sick individuals was performed using the accelerometer data. Patterns created from MTw sensor data were tested by KNN and SVM methods and their performances were compared. Reliable classification performance of the algorithms used in the study was provided with 10-fold crossvalidation. It will provide an estimate of how well the algorithms perform overall. In this method, the data set is divided into ten equal sections, so that each section will have a balanced number of samples from all categories. 9 of them were used to train the classifier, and the rest were used to assess the effectiveness of the classifiers. The average of the classification performances obtained is considered the final performance of the system. The following accuracy measurement was used to evaluate the performance of the approaches.

$$
\text { Accuracy }=\frac{T N+T P}{T P+T N+F P+F N} \times 100
$$

where TP, FP, TN and FN represent the number of true positives, false positives, true negatives and false negatives respectively.
In this study where only accelerometer data is used, the accuracy rates obtained according to different methods are shown in Figure 7. In this way, while showing the SVM, ANN and KNN methods according to different cross-validation on the $x$ axis, the accuracy rates of the methods are shown on the $y$ axis. The highest accuracy was obtained with the SVM method with $95.7 \%$.

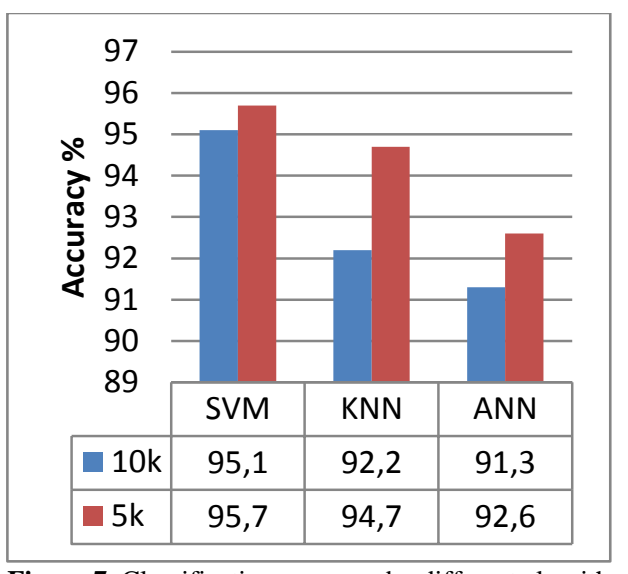

Figure 7. Classification accuracy by different algorithms

In this study, the confusion matrix obtained from different methods is shown in Table 6. 1 in the confusion matrix; shows the activity of sick individuals, 2 shows the activity of healthy individuals.

Table 6. The confusion matrix of KNN, SVM and ANN approaches

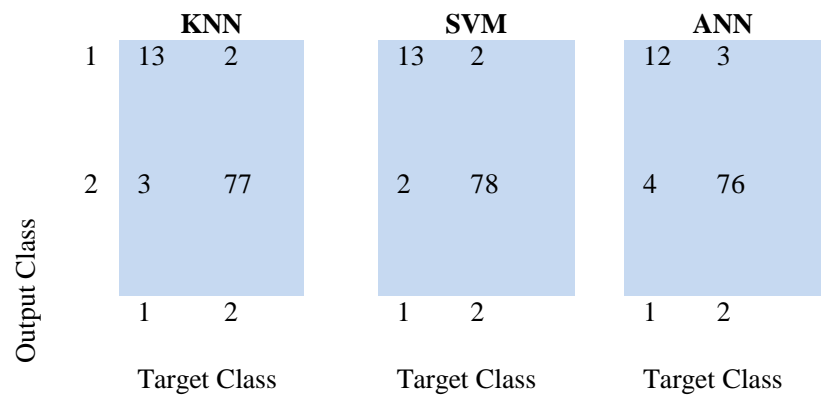

The accuracy obtained with twelve uses of KNN and SVM classifier models in total is given in Table 7.

Table 7. Accuracy rates for each model

\begin{tabular}{ll}
\hline Model & Accuracy $(\%)$ \\
\hline Fine KNN & $94.40 \%$ \\
Medium KNN & $90.00 \%$ \\
Coarse KNN & $87.80 \%$ \\
Cosine KNN & $88.90 \%$ \\
Cubic KNN & $90.00 \%$ \\
Weighted KNN & $90.00 \%$ \\
Linear SVM & $94.40 \%$ \\
Quadratic SVM & $95.60 \%$ \\
Cubic SVM & $95.60 \%$ \\
Fine Gaussian SVM & $87.80 \%$ \\
Medium Gaussian SVM & $91.10 \%$ \\
Coarse Gaussian SVM & $90.00 \%$ \\
\hline
\end{tabular}

\section{RESULTS}

This study used an experimental setup with the help of accelerometers to evaluate upper limb functions. Information was collected from patients and healthy individuals consisting of volunteers with the help of acceleration sensors. Classification processes of this 
obtained information were carried out using machine learning algorithms. When the results are analyzed, success is achieved with appropriate matches. This situation is interpreted as choosing appropriate attributes and obtaining a suitable representation of high dimensional data space in a low dimension. It also aimed to evaluate the use of an upper limb in non-clinical settings. This experimental study, designed under the guidance of doctors, provided a reliable basis.

In future studies, remote evaluations of stroke patients performing rehabilitation exercises at home are planned by medical experts. Since the accelerometer sensors used in the study have flexible belts, the patient can continue his daily life at home with wearable sensors. The web interface will be designed for remote evaluation. Thus, patients who have to go to the rehabilitation center can be monitored remotely by providing remote monitoring. More data will be collected in the future to develop the prediction model so that it can be applied to other stages of the Brunnstrom Staging.

\section{Limitations}

This study has different limitations: (a) Standing motion of the patient brings the effect of arm swing. The accelerometer we use unilaterally cannot eliminate this effect. (2) The current accelerometers cannot distinguish the motion model of the user as motor learning. (3) The participants' leaving the hospital in certain periods will not be enough to reflect the performance of the upper limb throughout the day. (4) There is also the opinion that accelerometers may not be as sensitive as conventional assessments to detect functional improvement. (5) The volunteer group participating in the study constitutes a small sample. This situation brings a limitation in terms of the generalizability of the findings.

\section{Information}

The data in this study were collected from 15 stroke patients and 80 healthy individuals. We would like to thank the students of Bingöl University School of Physical Education and Sports who participated in this study to form a healthy cluster and our patients who devotedly support us to finish the experiments. We also thank the staff of the Bingöl State Hospital Physical Medicine and Rehabilitation Department, who provided detailed guidance and assistance during the experiments.

\section{Declaration of Competing Interest}

We declare that we do not have any commercial or associative interest that represents a conflict of interest in connection with the work submitted.

\section{Ethics Statement}

We declare that this study does not require any ethical approval and letter in connection with the work submitted.

\section{REFERENCES}

[1] Go AS, Mozaffarian D, Roger VL, Benjamin EJ, Berry JD, Blaha MJ, et al. Heart Disease and Stroke Statistics - 2014 Update: A report from the American Heart Association. Circulation 2014. https://doi.org/10.1161/01.cir.0000441139.02102.8 0 .

[2] Songül DEVRIM SOYDEMIR. Acilde serebral inme endikasyonu ile yoğun bakım yatış kararı verilen kronik hemodiyaliz hastalarının demografik özellikleri, Natıonal institutes of health stroke skalası (nıhss) ve charlson komorbidite skorlarının (ccs) diğer hastalar ile karşılaştırılma. 2015.

[3] Lloyd-Jones D, Adams RJ, Brown TM, Carnethon M, Dai S, De Simone G, et al. Executive summary: Heart disease and stroke statistics-2010 update: A report from the american heart association. Circulation 2010. https://doi.org/10.1161/CIRCULATIONAHA.109. 192667.

[4] Gustavsson A, Svensson M, Jacobi F, Allgulander C, Alonso J, Beghi E, et al. Corrigendum to "Cost of disorders of the brain in Europe 2010" [Eur. Neuropsychopharmacol. 21 (2011) 718-779]. Eur Neuropsychopharmacol 2012. https://doi.org/10.1016/j.euroneuro.2012.01.001.

[5] Hancock N, Kilbride C. National clinical guideline for stroke. R Coll Physicians, UK 2012.

[6] Lange B, Chang CY, Suma E, Newman B, Rizzo AS, Bolas M. Development and evaluation of low cost game-based balance rehabilitation tool using the microsoft kinect sensor. Proc. Annu. Int. Conf. IEEE Eng. Med. Biol. Soc. EMBS, 2011. https://doi.org/10.1109/IEMBS.2011.6090521.

[7] Rosenbaum P, Stewart D. The World Health Organization International Classification of Functioning, Disability, and Health: A Model to Guide Clinical Thinking, Practice and Research in the Field of Cerebral Palsy. Semin Pediatr Neurol 2004. https://doi.org/10.1016/j.spen.2004.01.002.

[8] Tripoliti EE, Zervakis M, Fotiadis DI. Computerbased assessment of alzheimer's disease employing fMRI and/or EEG: A comprehensive review. Mod. Electroencephalogr. Assess. Tech. Theory Appl., 2014. https://doi.org/10.1007/7657_2014_70.

[9] Rigas G, Tzallas AT, Tsipouras MG, Bougia P, Tripoliti EE, Baga D, et al. Assessment of tremor activity in the parkinsons disease using a set of wearable sensors. IEEE Trans Inf Technol Biomed 2012. https://doi.org/10.1109/TITB.2011.2182616.

[10] Mazilu S, Blanke U, Hardegger M, Troster G, Gazit E, Dorfman M, et al. GaitAssist: A wearable assistant for gait training and rehabilitation in Parkinson's disease. 2014 IEEE Int. Conf. Pervasive Comput. Commun. Work. PERCOM Work. 2014, 2014. https://doi.org/10.1109/PerComW.2014.6815179.

[11] Ahlrichs C, Samà A, Lawo M, Cabestany J, Rodríguez-Martín D, Pérez-López C, et al. Detecting freezing of gait with a tri-axial accelerometer in Parkinson's disease patients. Med Biol Eng 2016. 
https://doi.org/10.1007/s11517-015-1395-3.

[12] Harun GÜNEŞ. Eeg/Emg Türü Zaman Serileri Kullanılarak Hareket Sinıflandırma İçin Derin Öğrenme Kullanımı. Fırat Üniversitesi, 2019.

[13] Ossig C, Antonini A, Buhmann C, Classen J, Csoti I, Falkenburger B, et al. Wearable sensor-based objective assessment of motor symptoms in Parkinson's disease. J Neural Transm 2016. https://doi.org/10.1007/s00702-015-1439-8.

[14] Patel S, Lorincz K, Hughes R, Huggins N, Growdon J, Standaert D, et al. Monitoring motor fluctuations in patients with parkinsons disease using wearable sensors. IEEE Trans Inf Technol Biomed 2009. https://doi.org/10.1109/TITB.2009.2033471.

[15] Mamorita N, Iizuka T, Takeuchi A, Shirataka M, Ikeda N. Development of a system for measurement and analysis of tremor using a threeaxis accelerometer. Methods Inf. Med., 2009. https://doi.org/10.3414/ME9243.

[16] Shull PB, Jirattigalachote W, Hunt MA, Cutkosky MR, Delp SL. Quantified self and human movement: A review on the clinical impact of wearable sensing and feedback for gait analysis and intervention. Gait Posture 2014. https://doi.org/10.1016/j.gaitpost.2014.03.189.

[17] Rudzińska M, Izworski A, Banaszkiewicz K, Bukowczan S, Marona M, Szczudlik A. Quantitative tremor measurement with the computerized analysis of spiral drawing. Neurol Neurochir Pol 2007.

[18] O’Suilleabhain PE, Dewey RB. Validation for tremor quantification of an electromagnetic tracking device. Mov Disord 2001. https://doi.org/10.1002/mds.1064.

[19] Norman KE, Edwards R, Beuter A. The measurement of tremor using a velocity transducer: Comparison to simultaneous recordings using transducers of displacement, acceleration and muscle activity. J Neurosci Methods 1999. https://doi.org/10.1016/S0165-0270(99)00091-6.

[20] Carod-Artal FJ, Egido JA. Quality of life after stroke: The importance of a good recovery. Cerebrovasc. Dis., 2009. https://doi.org/10.1159/000200461.

[21] Hajibandeh N, Faghihi F, Ranjbar H, Kazari H. Classifications of disturbances using wavelet transform and support vector machine. Turkish J Electr Eng Comput Sci 2017. https://doi.org/10.3906/elk-1511-124. 